\title{
Stop Codon
}

National Human Genome Research Institute (NHGRI)

\section{Source}

National Human Genome Research Institute (NHGRI). Stop Codon.
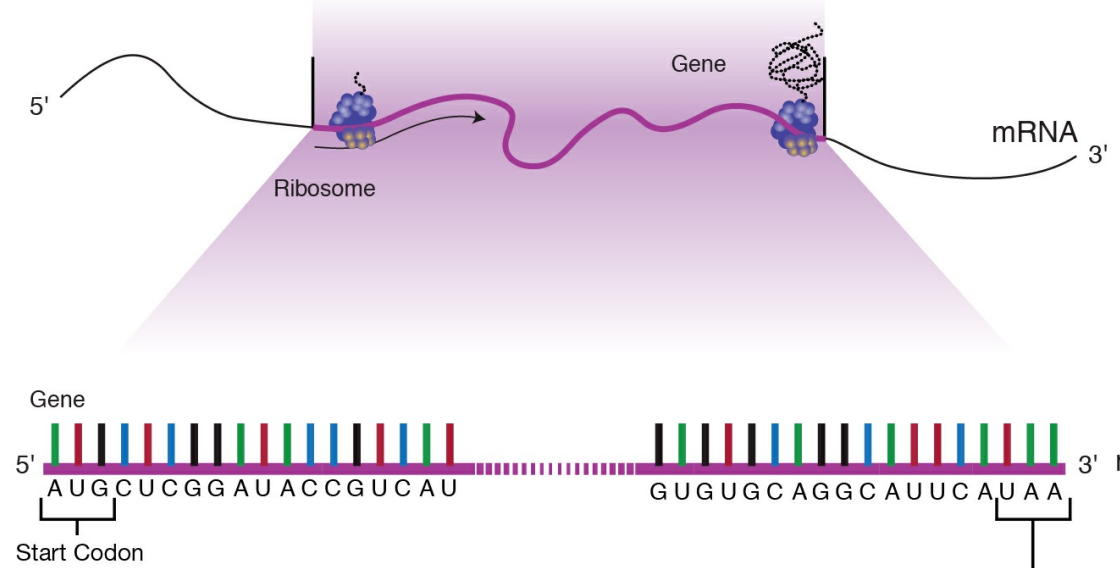

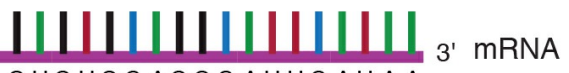
$G \cup G \cup G C A G G C A \cup \cup C A \cup A A$ Start Codon

A stop codon is a trinucleotide sequence within a messenger RNA (mRNA) molecule that signals a halt to protein synthesis. The genetic code describes the relationship between the sequence of DNA bases ( $\mathrm{A}, \mathrm{C}, \mathrm{G}$, and $\mathrm{T}$ ) in a gene and the corresponding protein sequence that it encodes. The cell reads the sequence of the gene in groups of three bases. Of the 64 possible combinations of three bases, 61 specify an amino acid, while the remaining three combinations are stop codons. 